Revista Brasileira de

Engenharia Agrícola e Ambiental

v. 12, n.5, p.465-470, 2008

Campina Grande, PB, UAEAg/UFCG - http://www.agriambi.com.br

agriambi

Protocolo 096.06 - 17/08/2006 • Aprovado em 29/01/2008

\title{
Eficiência produtiva de cultivares de arroz com divergência fenotípica
}

\author{
Cleber M. G uimarães ${ }^{1}$, Luís F. Stone ${ }^{1} \&$ Péricles de C. F. Neves $^{1}$
}

\begin{abstract}
RESU M O
0 objetivo do trabalho foi avaliar, fenotipicamente, as cultivares de arroz tradicionais Guarani e Caiapó, e as modernas, CIRAD L-141, Maravilha, BR IRGA 409 e Metica 1, por meio da associação entre os vários componentes da produtividade de grãos, para prover base de seleção genética em populações de plantas. 0 estudo foi conduzido na estação chuvosa do ano agrícola de 2003-2004, na área experimental da Embrapa Arroz e Feijão, em Santo Antônio de Goiás, GO . Em condições de sequeiro, com suplementação hídrica, as cultivares de arroz de terras altas CIRAD L-141, Guarani, Caiapó e Maravilha, apresentaram maiores índices de colheita e menores percentagens de esterilidade de espiguetas que as de arroz irrigado BR IRG A 409 e Metica 1. Concluiu-se que a maior produção de biomassa pelas cultivares de arroz irrigado não se refletiu na produtividade de grãos. A CIRAD L-141 por apresentar al ta área foliar, panículas densas com alto número de grãos e um comportamento intermediário em todos os componentes avaliados, como índice de colheita, massa dos grãos, fertilidade de perfilhos, perfilhamento, esterilidade de espiguetas e taxa de crescimento, produziu $12,5 \%$ a mais que a segunda mais produtiva. 0 aumento do índice de colheita e da massa dos grãos e a redução da esterilidade das espiguetas devido às suas altas correlações com a produtividade, são considerados prioritários em programas de melhoramento de arroz que visem obter cultivares mais produtivas.
\end{abstract}

Palavras-chave: O ryza sativa, índice de colheita, taxa de crescimento da cultura, índice de área foliar, perfilhamento

\section{Production efficiency of rice cultivars with phenotypic diversity}

\begin{abstract}
The objective of this study was to phenotypically evaluate the traditional rice cultivars G uarani and Caiapó, and the modern rice cultivars CIRAD L-141, Maravilha, BR IRGA 409, and Metica 1 through association among various yield components to establish a genetic selection base in plant population. The study was conducted during the rainy season of 2003-2004, at the Embrapa Rice \& Beans experimental station, in Santo Antônio de Goiás, Goiás, Brazil. With supplementary irrigation, the upland rice cultivars CIRAD L-141, Guarani, Caiapó, and M aravilha presented higher grain harvest indexes and lower spikelet sterility than the lowland cultivars BR IRGA 409 and Metica 1. It was concluded that the highest biomass yield of the lowland rice cultivars did not have an effect upon the grain yield. The upland cultivar CIRAD L-141, with high leaf area, panicles with high grain number and average performance of the agronomic components evaluated, such as harvest index, grain weight, tiller fertility, tillering, spikelet sterility and growth index, yielded 12.5\% higher than Guarani, the second best cultivar. The increase in grain harvest index and weight of grain and the reduction in spikelet sterility, due to their high correlation with grain yield, are considered high priority in the upland rice breeding programs for higher yields.
\end{abstract}

Key words: Oryza sativa, harvest index, crop growth rate, foliar area index, tillering 


\section{INTRODUÇÃO}

O ambiente provê a planta com fatores de crescimento enquanto os fatores da planta, ou seja, seus aspectos fenotípicos e genotípicos determinam, direta ou indiretamente, a utilização desses fatores externos (Pereira \& Machado, 1987). Os aspectos fenotípicos e genotípicos divergem, mesmo dentro da própria espécie; portanto, isto se reflete no crescimento e na produtividade.

A produtividade de uma cultura é o resultado final de todas as interações planta-ambiente; sobre esta inter-relação atua o melhoramento, procurando a melhor expressividade morfológica e econômica, em determinadas condições de ambiente (Agrawal et al., 1978; Amin, 1979; Ragarathinam $\&$ Raja, 1992). Saif-ur-Rasheed et al. (2002) concluíram que o aumento da produtividade de grãos das cultivares de arroz (Oryza sativa L.) exige a melhoria dos seus índices de fertilidade das espiguetas e de colheita e da produtividade de biomassa das plantas. Karimi \& Siddique (1991) notaram, em trigo (Triticum aestivum L.), em relação às cultivares antigas, que as modernas foram caracterizadas por maior taxa de crescimento relativo (TCR) durante a fase vegetativa; os autores acrescentaram que isto foi alcançado com índice de área foliar (IAF) inicial baixo, que persistiu durante o ciclo da planta e foi associado à alta taxa de crescimento da cultura (TCC) na antese e maior produtividade de grãos ao final do ciclo da planta. Por outro lado, as cultivares antigas apresentaram alto IAF durante a fase intermediária de desenvolvimento da cultura, declinando rapidamente com o aumento da temperatura e da deficiência hídrica no solo nessa fase, culminando com IAF e TCC baixos na antese e produtividade de grãos também baixa na colheita.

Stone \& Pereira (1994) constataram que, quanto maior for a área foliar, maior será a demanda da planta de arroz por água; observaram, ainda, que cultivares modernas de arroz comparativamente às tradicionais, apresentaram maiores IAF e duração da área foliar e que esta, em condições favorecidas de umidade no solo, se correlacionou positivamente com a produtividade de grãos. Noorbakhshian \& Rezai (1999), entretanto, afirmaram que o IAF na floração se correlacionou negativamente com a produtividade de grãos e foi maior nas cultivares tardias em relação às precoces.

Dutta et al. (2002) citaram que as cultivares indicas de arroz apresentaram menores porte, área foliar, taxa de infertilidade de perfilhos e esterilidade das espiguetas devido ao aumento da translocação de carboidratos para os grãos, o que poderia ser conseguido em plantas com folhas bandeiras mais largas e eretas e com folhas baixeiras menores, estreitas e horizontais. Conforme Pinheiro (1999), as novas cultivares de arroz de terras altas agregam qualidade dos grãos e alto potencial produtivo, além da distribuição de folhas mais eretas, o que possibilita o melhor aproveitamento da luz em razão da sua melhor distribuição no dossel foliar; esta arquitetura foliar diminui o auto-sombreamento, que ocorre com maior intensidade nas plantas com distribuição foliar horizontal, como nas cultivares tradicionais de arroz de terras altas, ou mesmo naquelas lançadas na fase inicial do programa de melhoramento de arroz, como a Guarani. Por outro lado, as novas cultivares de arroz, como a Maravilha, ao apresentarem folhas mais eretas têm diminuída sua capacidade competitiva com as plantas daninhas.

Objetivou-se, neste trabalho, avaliar, fenotipicamente, as cultivares de arroz tradicionais Guarani e Caiapó, e as modernas, CIRAD L-141, Maravilha, BR IRGA 409 e Metica 1, por meio da associação entre vários componentes da produtividade de grãos, para prover base de seleção genética em populações de plantas.

\section{MATERIAL E MÉTODOS}

O estudo foi conduzido em condições de campo no período das águas do ano agrícola de 2003-2004, na área experimental da Embrapa Arroz e Feijão, em Santo Antônio de Goiás, GO, de coordenadas geográficas $16^{\circ} 28^{\prime}$ de latitude sul, $49^{\circ} 17^{\prime}$ de longitude oeste e altitude de $823,77 \mathrm{~m}$, em sua estação agroclimática, em Latossolo Vermelho distrófico, de textura argilosa. A análise química inicial dos solos apresentou, na camada de $0-20 \mathrm{~cm}$ de profundidade, os seguintes resultados: $\mathrm{pH}\left(\mathrm{H}_{2} \mathrm{O}\right) 5,6 ; \mathrm{Ca}^{2+} 24,3 \mathrm{mmol}_{\mathrm{c}} \mathrm{dm}^{-3}, \mathrm{Mg}^{2+} 11,4$ $\mathrm{mmol}_{\mathrm{c}} \mathrm{dm}^{-3} ; \mathrm{Al}^{3+} 1,0 \mathrm{mmol}_{\mathrm{c}} \mathrm{dm}^{-3} ; \mathrm{P} 0,4 \mathrm{mg} \mathrm{dm}^{-3}$ e K 90,0 $\mathrm{mg} \mathrm{dm}^{-3}$, determinados segundo metodologia apresentada em Claessen (1997). Avaliaram-se duas cultivares tradicionais de arroz, Guarani e Caiapó, e quatro modernas, CIRAD L-141, Maravilha, BR IRGA 409 e Metica 1, no delineamento de blocos completos casualizados e quatro repetições; adotouse o espaçamento de $0,35 \mathrm{~m}$ entre fileiras e densidade de semeadura de 70 sementes por metro. Guarani, Caiapó, CIRAD L-141 e Maravilha, são cultivares desenvolvidas para condições de sequeiro, e as BR IRGA 409 e Metica 1 o são para condições de irrigação por inundação. Dentre as cultivares de sequeiro, a Maravilha é considerada a mais sensível ao déficit hídrico.

O preparo do solo foi o convencional e a adubação de base foi feita com 12, 48, 90, 20 e $20 \mathrm{~kg} \mathrm{ha}^{-1}$ de $\mathrm{N}, \mathrm{P}_{2} \mathrm{O}_{5}, \mathrm{~K}_{2} \mathrm{O}$, sulfato de zinco e FTE BR 12, respectivamente. A adubação de cobertura foi efetuada com $30 \mathrm{~kg} \mathrm{ha}^{-1}$ de $\mathrm{N}$, na fase de diferenciação floral. Aplicaram-se irrigações suplementares, quando necessário, e se efetuou o controle de plantas daninhas com oxadiazon, na dose de $800 \mathrm{~g}$ i.a. ha ${ }^{-1}$, enquanto as pulverizações preventivas contra brusone (Magnaporte grisea) foram efetuadas conforme recomendado para a cultura (Filippi \& Prabhu, 1998).

Avaliou-se a produtividade de grãos, o índice de colheita, a fertilidade de perfilhos, a densidade de perfilhos e panículas por $\mathrm{m}^{2}$, a massa de 100 grãos, a esterilidade de espiguetas, o número de grãos por panícula e a altura da planta. $\mathrm{O}$ índice de colheita foi calculado pela relação entre a massa dos grãos e a massa da matéria seca total da planta e a altura da planta, pela distância entre a superfície do solo e a extremidade das últimas folhas estendidas para cima. Determinou-se, também, a massa da matéria seca das plantas na época de colheita, com base em $0,7 \mathrm{~m}^{2}$. A secagem da biomassa foi efetuada em estufa, com circulação interna forçada de ar, a $70^{\circ} \mathrm{C}$, até massa constante, sendo esta indicada em balança de precisão. As amostragens para a determina- 
ção da análise de crescimento das plantas foram feitas aos 29, 36, 43, 57, 64, 71, 78, 85, 92, 99 e 106 dias após a emergência (DAE), para todas as cultivares, exceto para a Guarani, em virtude de apresentar ciclo mais curto, em que as avaliações foram efetuadas até os 99 DAE; a área foliar foi medida com o auxílio de um medidor de área foliar LI-COR, modelo LI 3100.

As análises de crescimento foram feitas com o auxílio do programa computacional elaborado por Portes \& Castro (1991) e baseadas no ajuste, pelo método dos quadrados mínimos dos dados de índice de área foliar, $\mathrm{em} \mathrm{m}^{2} \mathrm{~m}^{-2}$, e da massa da matéria seca, em kg ha-1, em relação ao tempo, em dias após a emergência. Utilizaram-se funções exponenciais quadráticas para o ajustamento dos dados (Pereira \& Machado, 1987; Portes \& Castro, 1991).

Os índices fisiológicos estimados a partir das funções ajustadas foram: acúmulo de matéria seca da planta, em $\mathrm{kg} \mathrm{ha}^{-1}$, evolução do índice de área foliar, $\mathrm{em}^{2} \mathrm{~m}^{-2}$, e taxa de crescimento da cultura, em $\mathrm{kg} \mathrm{ha}^{-1} \mathrm{dia}^{-1}$.

\section{RESULTADOS E DISCUSSÃO}

Encontraram-se diferenças significativas entre as cultivares, em todas as características avaliadas (Tabela 1), como resultado da variabilidade genética, que condicionou diferentes arquitetura de planta, ciclo e adaptação às condições de sequeiro.

As maiores produtividades em $\mathrm{kg} \mathrm{ha}^{-1}$, foram da CIRAD L-141 (3.560), Guarani (3.162) e Caiapó (2.926), que superaram em 172,6, 142,1 e 124,0\%, respectivamente, a BR IRGA $409\left(1306 \mathrm{~kg} \mathrm{ha}^{-1}\right)$, que foi a de menor produtividade. Essa cultivar não diferiu significativamente da Maravilha e nem da Metica 1 que, por sua vez, não diferiram das demais cultivares estudadas.

A cultivar Guarani, do tipo tradicional, de ciclo curto e a mais adaptada ao sistema de sequeiro (Santos, 1990), apresentou índice de colheita de $52,7 \%$, significativamente superior aos das outras cultivares. O menor índice de colheita foi de 11,8\% da BR IRGA 409, seguido da Metica $1 \mathrm{com}$ $30,3 \%$, mostrando que essas cultivares de arroz irrigado tiveram menor adaptabilidade ao ambiente de sequeiro em que foram cultivadas. Elas apresentaram também índices de fertilidade de perfilhos inferiores significativamente às demais cultivares que, sem dúvidas, contribuíram para seu pior com- portamento produtivo mesmo apresentando os maiores valores de perfilhamento, que resultaram na maior ocorrência de panículas $\mathrm{m}^{-2}$; a cultivar Metica 1 produziu o maior número de panículas $\mathrm{m}^{-2}$, 346, seguido da BR IRGA 409 com 230 panículas $\mathrm{m}^{-2}$, que não diferiu significativamente das Maravilha (182 panículas $\mathrm{m}^{-2}$ ) e Guarani (158 panículas $\mathrm{m}^{-2}$ ). Soares et al. (1990) não observaram influência consistente do aumento do perfilhamento sobre a produtividade do arroz.

Por outro lado, a cultivar Guarani mostrou grãos com maior massa, 3,04 g por 100 grãos, característica típica das cultivares tradicionais de sequeiro mas não diferiu significativamente da Caiapó, CIRAD L-141, Maravilha e nem da Metica 1, com massa de 2,81, 2,66, 2,20 e 2,24 g por 100 grãos, respectivamente.

A cultivar BR IRGA 409, desenvolvida para condição de irrigação por inundação, apresentou a maior esterilidade de espiguetas, 40,6\%. O segundo grupo, com maior esterilidade de espiguetas, se compunha das cultivares Metica 1, Maravilha e CIRAD L-141, todas também desenvolvidas para ambiente de maior disponibilidade de água, exceto a CIRAD L-141; este comportamento pode ser explicado pelo ambiente de sequeiro em que foram submetidas, o que contribuiu para a maior incidência de brusone; esta doença é responsável, em geral, pela esterilidade de espiguetas, conforme relataram Prabhu et al. (1986) e Guimarães \& Prabhu (2002). Prabhu \& Filippi (2006) acrescentam que as condições edafo-climáticas do ecossistema de sequeiro favorece o desenvolvimento da doença, pela maior disponibilidade de nitrogênio na forma de nitrato e pelos períodos geralmente mais longos de persistência das gotículas de orvalho na superfície foliar, em conseqüência das temperaturas noturnas mais baixas.

Embora não tenham diferido significativamente de outras cultivares, a CIRAD L-141 apresentou o maior número de grãos por panícula, 164, e a Guarani o menor, 87, o que certamente contribuiu para os $12,5 \%$ de diferença de produtividade entre elas, apesar da não significância estatística.

Entre as características estudadas, o índice de colheita, a massa de 100 grãos e a esterilidade de espiguetas apresentaram maior correlação com a produtividade de grãos, com valores de $\mathrm{R}$ iguais, respectivamente, a 0,921, 0,868 e -0,938 (Tabela 2) significando que o aumento da produtividade se dá pelo aumento do índice de colheita e da massa de 100 grãos e, ainda, devido à redução da esterilidade de espigue-

Tabela 1. Produtividade e componentes agronômicos das cultivares de arroz estudadas

\begin{tabular}{|c|c|c|c|c|c|c|c|c|c|}
\hline Cultivar & $\begin{array}{l}\text { Produtividade } \\
\left(\mathrm{kg} \mathrm{ha}^{-1}\right)\end{array}$ & $\begin{array}{l}\text { Índice de } \\
\text { colheita (\%) }\end{array}$ & $\begin{array}{l}\text { Perfilhos } \\
\text { férteis (\%) }\end{array}$ & $\begin{array}{l}\text { Perfilhos } \\
\left(n-m^{-2}\right)\end{array}$ & $\begin{array}{l}\text { Panículas } \\
\left(\mathrm{n}-\mathrm{m}^{-2}\right)\end{array}$ & $\begin{array}{l}\text { Massa de } 100 \\
\text { grãos }(\mathrm{g})\end{array}$ & $\begin{array}{c}\text { Esterilidade de } \\
\text { espiguetas } \\
(\%)\end{array}$ & $\begin{array}{c}\text { Grãos por } \\
\text { Panícula (n-) }\end{array}$ & $\begin{array}{l}\text { Altura } \\
(\mathrm{cm})\end{array}$ \\
\hline Guarani & $3.162 \mathrm{a}$ & $52,7 \mathrm{a}$ & 98,8 a & $160 \mathrm{c}$ & 158 bc & $3,04 \mathrm{a}$ & $5,5 \mathrm{c}$ & $87 c$ & $99,7 a b$ \\
\hline Caiapó & $2.926 \mathrm{a}$ & $43,5 \mathrm{~b}$ & $97,2 \mathrm{a}$ & $152 \mathrm{C}$ & $149 \mathrm{c}$ & $2,81 \mathrm{a}$ & $8,3 \mathrm{c}$ & $140 a b$ & 125,5 a \\
\hline CIRAD L-141 & $3.560 \mathrm{a}$ & $44,1 \mathrm{~b}$ & $96,9 \mathrm{a}$ & $154 \mathrm{C}$ & $150 \mathrm{C}$ & $2,66 \mathrm{a}$ & $10,0 \mathrm{bc}$ & $164 a$ & $100,4 a b$ \\
\hline Maravilha & $2.776 a b$ & $44,6 \mathrm{~b}$ & $96,4 \mathrm{a}$ & 188 bc & $182 b c$ & $2,20 a b$ & $11,5 b c$ & $137 a b$ & $100,8 \mathrm{ab}$ \\
\hline BR IRGA 409 & $1.306 \mathrm{~b}$ & $11,8 d$ & $92,8 \mathrm{ab}$ & $250 \mathrm{~b}$ & $230 \mathrm{~b}$ & $1,61 \mathrm{~b}$ & $40,6 \mathrm{a}$ & $135 a b$ & $85,7 \mathrm{~b}$ \\
\hline Metica 1 & $2.392 \mathrm{ab}$ & $30,3 \mathrm{c}$ & $81,9 \mathrm{~b}$ & $393 a$ & $346 a$ & $2,24 a b$ & $23,2 b$ & $116 b c$ & $78,7 \mathrm{~b}$ \\
\hline $\mathrm{F}$ & $5,57 * *$ & $78,95 * *$ & $4,10 * *$ & $32,94 * *$ & $23,66^{* *}$ & $0,20 * *$ & $19,41^{* *}$ & $7,10 * *$ & $7,94 * *$ \\
\hline CV $(\%)$ & 24,63 & 8,71 & 6,56 & 15,13 & 15,59 & 18,28 & 36,51 & 15,09 & 11,59 \\
\hline
\end{tabular}

Valores seguidos da mesma letra na coluna não diferem significativamente a $5 \%$ de probabilidade, pelo teste de Tukey. **- $\mathrm{F}$ significativo a $1 \%$ de probabilidade 
Tabela 2. Coeficientes de correlação entre produtividade (PROD), índice de colheita (IC), fertilidade de perfilhos (FPERF), densidade de perfilhos (DPERF) e de panículas (DPAN), massa de 100 grãos (M S100), esterilidade de espiguetas (EE), grãos por panícula (GPAN) e altura das plantas (ALT) das cultivares de arroz estudadas

\begin{tabular}{|c|c|c|c|c|c|c|c|c|}
\hline & $\begin{array}{l}\text { PROD } 1 \\
\left(\mathrm{~kg} \mathrm{ha}^{-1}\right)\end{array}$ & $\begin{array}{c}\text { IC } \\
(\%)\end{array}$ & $\begin{array}{c}\text { FPERF } \\
(\%)\end{array}$ & $\begin{array}{l}\text { DPERF } \\
\left(n^{0}-m^{-2}\right)\end{array}$ & $\begin{array}{l}\text { DPAN } \\
\left(n^{0} m^{-2}\right)\end{array}$ & $\begin{array}{c}\text { MS100 } \\
(\mathrm{g})\end{array}$ & $\begin{array}{c}\mathrm{EE} \\
(\%)\end{array}$ & $\begin{array}{c}\text { GPAN } \\
(\mathrm{n} \cap)\end{array}$ \\
\hline IC (\%) & $\begin{array}{l}0,921 \\
0,005\end{array}$ & - & - & - & & - & - & - \\
\hline FPERF (\%) & $\begin{array}{l}0,455 \\
0,353\end{array}$ & $\begin{array}{l}0,542 \\
0,253\end{array}$ & - & - & & 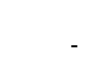 & - & - \\
\hline $\begin{array}{l}\text { DPERF } \\
\left(n^{0} m^{-2}\right)\end{array}$ & $\begin{array}{r}-0,536 \\
0,260\end{array}$ & $\begin{array}{r}-0,578 \\
0,216\end{array}$ & $\begin{array}{r}-0,987 \\
<0,001\end{array}$ & - & & - & - & - \\
\hline $\begin{array}{l}\text { DPAN } \\
\left(n-m^{-2}\right)\end{array}$ & $\begin{array}{r}-0,542 \\
0,041\end{array}$ & $\begin{array}{r}-0,577 \\
0,217\end{array}$ & $\begin{array}{r}-0,983 \\
<0,001\end{array}$ & $\begin{array}{r}1,000 \\
<0,001\end{array}$ & - & - & - & - \\
\hline MS100 (g) & $\begin{array}{l}0,868 \\
0,017\end{array}$ & $\begin{array}{c}0,897 \\
0,01\end{array}$ & $\begin{array}{l}0,470 \\
0,336\end{array}$ & $\begin{array}{r}-0,523 \\
0,274\end{array}$ & $\begin{array}{r}-0,529 \\
0,003\end{array}$ & - & - & - \\
\hline $\mathrm{EE}(\%)$ & $\begin{array}{r}-0,938 \\
0,003\end{array}$ & $\begin{array}{r}-0,990 \\
<0,001\end{array}$ & $\begin{array}{r}-0,532 \\
0,264\end{array}$ & $\begin{array}{l}0,587 \\
0,206\end{array}$ & $\begin{array}{l}0,589 \\
0,070\end{array}$ & $\begin{array}{r}-0,912 \\
0,007\end{array}$ & - & - \\
\hline GPAN (no) & $\begin{array}{l}0,095 \\
0,856\end{array}$ & $\begin{array}{r}-0,177 \\
0,733\end{array}$ & $\begin{array}{l}0,130 \\
0,804\end{array}$ & $\begin{array}{r}-0,235 \\
0,649\end{array}$ & $\begin{array}{r}-0,247 \\
0,632\end{array}$ & $\begin{array}{r}-0,264 \\
0,608\end{array}$ & $\begin{array}{l}0,089 \\
0,864\end{array}$ & - \\
\hline $\operatorname{ALT}(\mathrm{cm})$ & $\begin{array}{l}0,009 \\
0,283\end{array}$ & $\begin{array}{l}0,577 \\
0,216\end{array}$ & $\begin{array}{l}0,713 \\
0,098\end{array}$ & $\begin{array}{r}-0,780 \\
0,055\end{array}$ & $\begin{array}{r}-0,787 \\
0,051\end{array}$ & $\begin{array}{l}0,606 \\
0,188\end{array}$ & $\begin{array}{r}-0,653 \\
0,145\end{array}$ & $\begin{array}{l}0,251 \\
0,626\end{array}$ \\
\hline
\end{tabular}

${ }^{1}$ Em cada coluna o primeiro valor corresponde ao coeficiente de correlação e o segundo à significância

tas; assim, esses componentes foram os responsáveis pelo desempenho produtivo da cultivar Guarani. No caso da CIRAD L-141, apesar dos valores desses componentes não estarem tão otimizados quanto na Guarani, o maior número de grãos por panícula contribuiu para elevar o seu desempenho produtivo. Saif-ur-Rasheed et al. (2002) verificaram que o índice de colheita e a esterilidade de espiguetas contribuíram, respectivamente, com 66,5 e $87,3 \%$ da variabilidade na produtividade de grãos. Soares et al. (1990) também notaram correlação positiva e significativa entre produtividade de grãos e massa de 100 grãos e porcentagem de grãos cheios; essas características foram consideradas prioritárias em programas de melhoramento de arroz que visem obter cultivares mais produtivas. Rangel et al. (1980) constataram correlação positiva e significativa entre produtividade de grãos e porcentagem de grãos cheios mas a correlação entre produtividade e massa de 100 grãos foi negativa.

A cultivar Maravilha apresentou crescimento lento do IAF, o que contribuiu para a sua baixa TCC durante todo o seu ciclo de desenvolvimento em comparação com as demais cultivares, resultando também no menor acúmulo de biomassa da parte aérea (Figura 1, Tabela 3). Como esta cultivar foi desenvolvida para sistemas de produção altamente tecnificados (Breseghello et al., 1998), de preferência com irrigação suplementar por aspersão, provavelmente não se adaptou ao sistema de produção convencional adotado neste trabalho. A Guarani, classificada como precoce, apresentou TCCs mais altas em comparação com as outras cultivares de terras altas, Caiapó, CIRAD L-141 e Maravilha, classificadas como de ciclo médio, atingindo o máximo valor, $162 \mathrm{~kg} \mathrm{ha}^{-1} \mathrm{dia}^{-1}$, aos 66 DAE. Este alto vigor de crescimento da Guarani na fase inicial de desenvolvimento da planta lhe confere maior capacidade competitiva com as plantas daninhas, uma característica típica das cultivares tradicionais e precoces de arroz de terras altas (Santos, 1990; Fageria et al., 2006).

As cultivares BR IRGA 409, Metica 1 e Caiapó, foram as de maior acúmulo final de biomassa da parte aérea (Figura 1), explicado pelas também maiores TCCs entre as cultivares avaliadas; entretanto, o desempenho dessas taxas ao longo do ciclo de desenvolvimento das plantas foi diferente; a cultivar Metica 1 apresentou, desde a fase inicial, a maior TCC e

Tabela 3. Acúmulo de matéria seca, taxa de crescimento da cultura e índice de área foliar das seis cultivares de arroz estudadas

\begin{tabular}{|c|c|c|}
\hline Cultivar & Equação de regressão & $\overline{R^{2}}$ \\
\hline \multicolumn{3}{|c|}{ Acúmulo de matéria seca $\left(\mathrm{kg} \mathrm{ha}^{-1}\right)$} \\
\hline Guarani & $Y=98,34281 e^{0,07973684 x-0,0003277574 \times 2}$ & $0,98 * *$ \\
\hline Caiapó & $Y=69,0 e^{0,08241738 x-0,0003004662 \times 2}$ & $0,99 * *$ \\
\hline CIRAD L-141 & $Y=64,11246 e^{0,08508235 x-0,0003343283 \times 2}$ & $0,99 * *$ \\
\hline Maravilha & $Y=78,27984 e^{0,0710006 x-0,0002389813 \times 2}$ & $0,99 * *$ \\
\hline BR IRGA 409 & $Y=137,7261 e^{0,07575947 x-0,0003015177 \times 2}$ & $0,99 * *$ \\
\hline Metica 1 & $Y=80,17073 e^{0,08937208 x-0,0003749464 \times 2}$ & $0,99 * *$ \\
\hline \multicolumn{3}{|c|}{ Taxa de crescimento da cultura ( $\left.\mathrm{kg} \mathrm{ha}^{-1} \mathrm{dia}^{-1}\right)$} \\
\hline Guarani & $Y=4,019231 e^{0,106704 x-0,0007692685 \times 2}$ & $0,99 * *$ \\
\hline Caiapó & $Y=4,739198 e^{0,0835883 x-0,0004244872 \times 2}$ & $0,99 * *$ \\
\hline CIRAD L-141 & $Y=4,042205 e^{0,09080379 x-0,0005167448 \times 2}$ & $0,99 * *$ \\
\hline Maravilha & $Y=4,9563 e^{0,069636 x-0,0003259 x 2}$ & $0,99 * *$ \\
\hline BR IRGA 409 & $Y=7,509063 e^{0,08265188 x-0,0004977352 \times 2}$ & $0,99 * *$ \\
\hline Metica 1 & $Y=4,33604 e^{0,1032937 x-0,0006493 \times 2}$ & $0,99 * *$ \\
\hline \multicolumn{3}{|c|}{ Índice de área foliar $\left(\mathrm{m}^{2} \mathrm{~m}^{-2}\right)$} \\
\hline Guarani & $Y=0,08642324 e^{0,1011783 x-0,0007281733 \times 2}$ & $0,93 * *$ \\
\hline Caiapó & $Y=0,0494966 \mathrm{e}^{0,1123568 \mathrm{x}-0,0006888962 \times 2}$ & $0,99 * *$ \\
\hline CIRAD L-141 & $Y=0,06880571 e^{0,1001176 x-0,0005800506 \times 2}$ & $0,99 * *$ \\
\hline Maravilha & $Y=0,06214256 \mathrm{e}^{0,09117071 \times-0,0004912699 \times 2}$ & $0,99 * *$ \\
\hline BR IRGA 409 & $Y=0,0874608 e^{0,09712291 \times-0,0005882287 \times 2}$ & $0,97 * *$ \\
\hline Metica 1 & $Y=0,04681268 e^{0,1151603 x-0,0006711097 \times 2}$ & $0,98 * *$ \\
\hline
\end{tabular}


A.

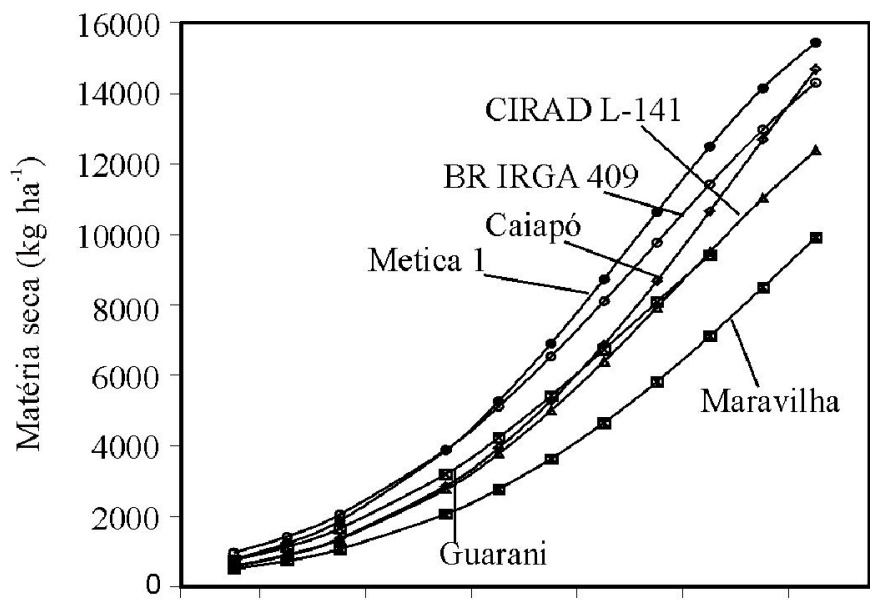

B.

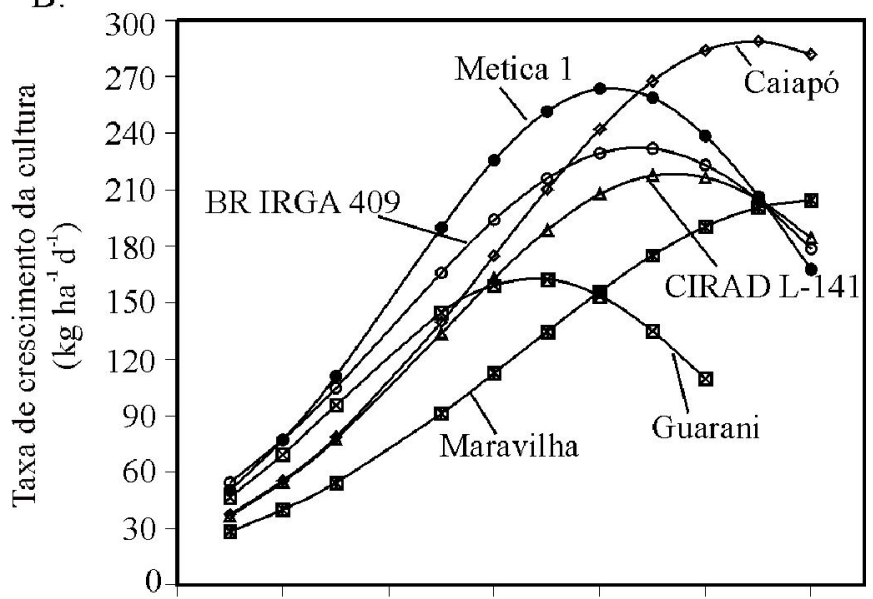

C.

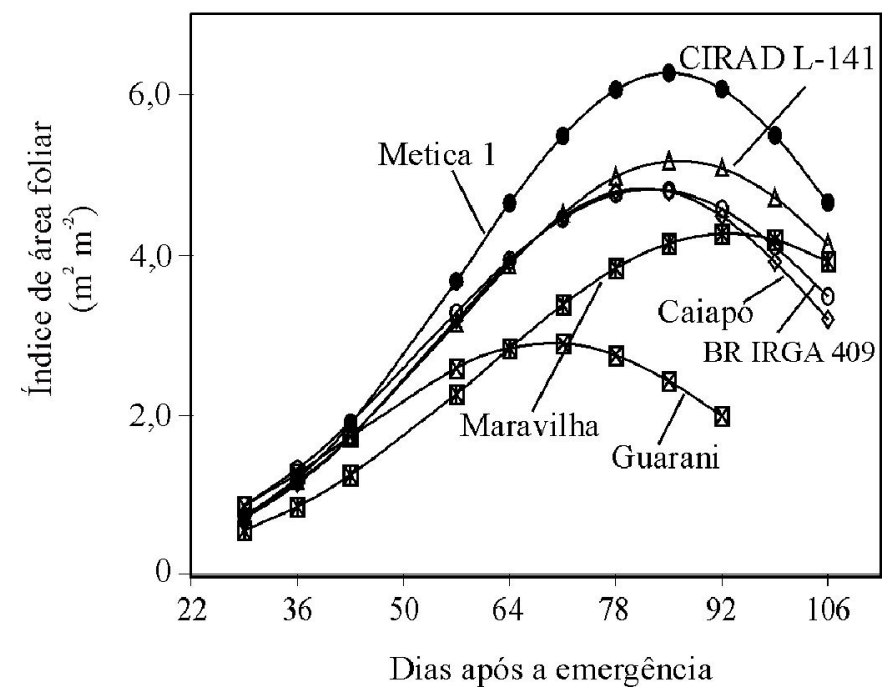

Figura 1. Acúmulo de matéria seca, taxa de crescimento da cultura e índice de área foliar das cultivares de arroz Guarani, Caiapó, CIRAD L-141, Maravilha, BR IRGA 409 e Metica 1

seu máximo foi registrado aos 80 DAE, com $264 \mathrm{~kg} \mathrm{ha}^{-1} \mathrm{dia}^{-1}$, a Caiapó, com TCC inicial baixa, maior apenas que a apresentada pela Maravilha, manteve constantes aumentos desse índice, alcançando o maior valor, entre as cultivares avalia- das aos 98 DAE com $289 \mathrm{~kg} \mathrm{ha}^{-1} \mathrm{dia}^{-1}$, enquanto na BR IRGA 409 o comportamento foi intermediário. A evolução desse índice conferiu distintas produtividades de grãos aos genótipos devido a diferenças na translocação dos fotossintatos para os diferentes sítios de armazenamento. Entre as três cultivares, a Caiapó foi a mais eficiente no uso dos fotossintatos para a produção de grãos ao apresentar índice de colheita de 43,5\% (Tabela 1).

A cultivar Maravilha apresentou o menor crescimento do IAF, entre as cultivares estudadas, durante quase todo o período de avaliação, exceto ao observado na cultivar Guarani, com um exuberante crescimento do IAF na fase inicial do experimento e o manteve alto até aproximadamente $40 \mathrm{DAE}$, quando então começou a diminuir sua taxa de crescimento, mantendo valores acima apenas dos observados na cultivar Maravilha até os $64 \mathrm{DAE}$; seu máximo de $2,9 \mathrm{~m}^{2} \mathrm{~m}^{-2}$ foi observado aos 70 DAE; a cultivar Metica 1 apresentou os maiores IAF, seguida da cultivar CIRAD L-141 e o alto IAF e o índice de colheita desta última cultivar lhe conferiram a maior produtividade de grãos, enquanto o alto IAF da Metica 1, assim como alto TCC (Figura 1), não lhe conferiram alta produtividade devido ao baixo índice de colheita (Tabela 1), ou seja, baixa capacidade de armazenar carboidratos nos grãos nas condições edafo-climáticas de condução do trabalho. Dutta et al. (2002) também concluíram que os altos IAF das cultivares locais resultaram em baixo índice de colheita.

\section{CONCLUSÕES}

1. A maior produção de biomassa pelas cultivares de arroz irrigado não se refletiu na produtividade de grãos.

2. A CIRAD L-141 por apresentar alta área foliar, panículas densas com alto número de grãos e um comportamento intermediário em todos os componentes avaliados, como índice de colheita, massa dos grãos, fertilidade de perfilhos, perfilhamento, esterilidade de espiguetas e taxa de crescimento, produziu $12,5 \%$ a mais que a segunda cultivar mais produtiva.

3. O aumento do índice de colheita e da massa dos grãos, e a redução da esterilidade das espiguetas devido às suas altas correlações com a produtividade, são considerados prioritários em programas de melhoramento de arroz que visem obter cultivares mais produtivas.

\section{LITERATURA CITADA}

Agrawal, R. K.; Lal, J. P.; Richharia, A. K. Note on selection indices and path-coefficients in semi-dwarf rice varieties. Indian Journal of Agricultural Science, v.48, p.58-60, 1978.

Amin, E. A. Correlation and path-coefficient analysis in some short stature rice cultivars and strains. International Rice Commission Newsletter, v.28, p.19-21, 1979.

Breseghello, F.; Castro, E. da M. de; Morais, O. P. Cultivares de arroz. In: Breseghello, F.; Stone, L. F. (ed.). Tecnologias para o arroz de terras altas. Santo Antônio de Goiás: Embrapa Arroz e Feijão, 1998. p.41-53. 
Claessen, M. E. C. (Org.). Manual de métodos de análise de solo. 2.ed. rev. atual. Rio de Janeiro: Embrapa CNPS, 1997. 212 p. Documentos, 1 .

Dutta, R. K.; Mia, M. A. B.; Khanam, S. Plant architecture and growth characteristics of fine grain and aromatic rices and their relation with grain yield. International Rice Commission Newsletter, v.51, p.51-56, 2002.

Fageria, N. K.; Baligar, V. C.; Clark, R. B. Physiology of crop production. New York: The Haworth Press, 2006. 345p.

Filippi, M.C.; Prabhu, A.S. Doenças do arroz e seu controle. In: Breseghello, F.; Stone, L. F. (ed.). Tecnologia para o arroz de terras altas. Santo Antônio de Goiás: Embrapa Arroz e Feijão, 1998. p.139-161.

Guimarães, C. M.; Prabhu, A. S. Adubação orgânica no arroz de terras altas: Relacionamentos entre brusone, esterilidade de espiguetas e produtividade. Santo Antônio de Goiás: Embrapa Arroz e Feijão, 2002. 2p. Comunicado Técnico, 42.

Karimi, M. M.; Siddique, K. H. Crop growth and relative growth rates of old and modern wheat cultivars. Australian Journal of Agricultural Research, v.42, p.13-20, 1991.

Noorbakhshian, J.; Rezai, A. Study of correlation between some traits and grain yield in rice cultivars using path analysis. Iranian Journal of Crop Science, v.1, n.4, p.55-65, 1999.

Pereira, A. R.; Machado, E. C. Análise quantitativa do crescimento de comunidades vegetais. Campinas: IAC, 1987. 33p. Boletim Técnico, 114.

Pinheiro, B. da S. Características morfofisiológicas da planta relacionadas à produtividade. In: Vieira, N. R. de A.; Santos, A. B. dos; Sant'Ana, E. P. (ed.). A cultura do arroz no Brasil. Santo Antônio de Goiás: Embrapa Arroz e Feijão, 1999. p.116-147.
Portes, T. de A.; Castro Jr., L.G. Análise de crescimento de plantas: Um programa computacional auxiliar. Revista Brasileira de Fisiologia Vegetal, v.3, n.1, p.53-56, 1991.

Prabhu, A. S.; Faria, J. C. de; Carvalho, J. R. P. de. Efeito da brusone sobre a matéria seca, produção de grãos e seus componentes, em arroz de sequeiro. Pesquisa Agropecuária Brasileira, v.21, n.5, p.495-500, 1986.

Prabhu, A. S.; Filippi, M. C. Resistência da cultivar no manejo integrado da brusone. In: Filippi, M. C.; Prabhu, A. S. (ed.). Brusone em arroz: Controle genético, progresso e perspectivas. Santo Antônio de Goiás: Embrapa Arroz e Feijão, 2006. p.321-387.

Ragarathinam, S.; Raja, V. D. G. Correlation and path analysis in some rice varieties under alkaline stress. Madras Agricultural Journal, v.79, p.374-378, 1992.

Rangel, P. H. N.; Galvão, J. D.; Silva, A. A. Correlações fenotípicas, genotípicas e de ambiente em variedade de arroz (Oryza sativa L.). Revista Ceres, v.27, n.105, p.188-195, 1980.

Saif-ur-Rasheed, M.; Sadaqat, H. A.; Babar, M. Correlation and path co-efficient analysis for yield and its components in rice (Oryza sativa L.). Asian Journal of Plant Sciences, v.1, n.3, p.241-244, 2002.

Santos, A. B. dos. Comportamento de cultivares de arroz de sequeiro em diferentes populações de plantas, com e sem irrigação suplementar. Piracicaba: USP, 1990. 94p. Tese Doutorado

Soares, P. C.; Silva, J. C.; Rangel, P. H. N.; Cutrim, V. dos A.; Castro, E. da M.; Cruz, C. D. Correlações coeficientes de trilha de caracteres do arroz cultivado em várzea úmida ou sob irrigação com inundação contínua. Revista Ceres, v.37, n.209, p.1-15, 1990.

Stone, L. F.; Pereira, A. L. Sucessão arroz-feijão irrigados por aspersão. Efeito de espaçamento entre linhas, adubação e cultivar no crescimento, desenvolvimento radicular e consumo d'água do arroz. Pesquisa Agropecuária Brasileira, v.29, n.10, p.1577-1592, 1994. 